\title{
Airborne sun photometer PLASMA: concept, measurements, comparison of aerosol extinction vertical profile with lidar
}

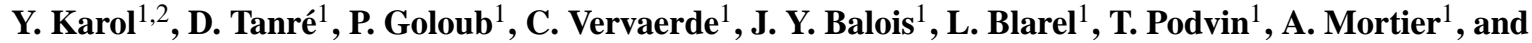 \\ A. Chaikovsky ${ }^{2}$ \\ ${ }^{1}$ Laboratoire d'Optique Atmosphérique (LOA), UMR8518, CNRS - Université des Sciences et Technologies de Lille, \\ 59655 Villeneuve d'Ascq, France \\ ${ }^{2}$ B. I. Stepanov Institute of Physics National Academy of Sciences of Belarus, 68, Nezavisimosti av., 220072 Minsk, Belarus
}

Correspondence to: Y. Karol (yana.karol@ed.univ-lille1.fr)

Received: 1 August 2012 - Published in Atmos. Meas. Tech. Discuss.: 19 September 2012

Revised: 5 August 2013 - Accepted: 5 August 2013 - Published: 16 September 2013

\begin{abstract}
A 15-channel airborne sun-tracking photometer has been developed. The instrument provides aerosol optical depths over a wide spectral range $(0.34-2.25 \mu \mathrm{m})$ with an accuracy $(\triangle \mathrm{AOD})$ of approximately 0.01 . Taking measurements at different altitudes allow us to derive the aerosol extinction vertical profile. Thanks to the wide spectral range of the instrument, information on the aerosol size distribution along the vertical is also available.
\end{abstract}

\section{Introduction}

Atmospheric aerosols play a role in the earth radiative budget (see, for example, Hansen et al., 1997; Ramanathan et al., 2001 or Kaufman et al., 2002). Due to their interaction with solar and thermal radiation, aerosols first cool the atmosphere-surface system (aerosol direct effect) and by absorbing sunlight in the atmosphere, they further cool the surface but warm the atmosphere. They also modify the temperature and humidity profiles which creates a more stable temperature profile that results in less cumulus cloud cover (semi-direct effect) (Hansen et al., 1997; Koren et al., 2004). Aerosols also impact the cloud properties by acting as cloud condensation nuclei and ice nuclei (indirect effects). To investigate aerosol-cloud interactions, it is important to determine the 3-D distribution of aerosol properties. There are several satellite sensors (imagers or scanners) that provide a 2-D distribution but the aerosol vertical repartition is not sampled. Satellite missions that include lidars such as CALIPSO (Winker et al., 2010) are useful tools for measuring vertical profiles of aerosols on the satellite track; however, elastic backscatter lidars have limitations since the lidar equation cannot be solved without an additional constraint such as independent optical depth measurement.

An airborne sun-tracking photometer named PLASMA (for Photomètre Léger Aéroporté pour la Surveillance des Masses d'Air) has been developed. Aerosol optical depths (AOD) at several wavelengths are derived from measurements of the extinction of solar radiation by molecular and aerosol scattering and absorption processes. Aerosol size distribution information can be retrieved from the AOD spectral dependence when the spectral range is large enough (King et al., 1978). Naturally, flying at different altitudes provides the information along the vertical.

Deriving photometric AODs is quite obvious as long as the instrument is well calibrated. There is no analog to the restrictive satellite constraint of signal contamination by highly reflective pixels and there is comparatively little dependence on particle properties of the aerosols. Indeed sun photometric measurements such as those made by AERONET (Holben et al., 1998) are the principal means of validating satellitebased AOD retrievals (Remer et al., 2005; Kahn et al., 2010; Tanré et al., 2011). With an airborne version like PLASMA, we can easily sample different locations within a few minutes. It can also be used to validate extinction vertical profiles obtained from ground-based or space-borne lidars such as CALIOP on CALIPSO (Winker et al., 2010).

Similar airborne sun photometers from last decades were successfully developed (Matsumoto et al., 1987; Schmid et al., 2003; Asseng et al., 2004). Compared to AATS-14 


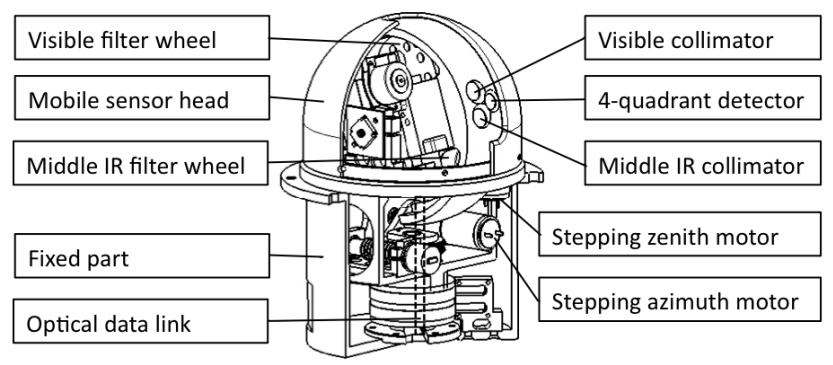

Fig. 1. PLASMA scheme.

(Ames Airborne Tracking Sun photometer) and FUBISSASA2 (Free University Berlin Integrated Spectrographic System - Aureole and Sun Adapter), the spectral range is similar. The main advantage of PLASMA is its small size and lightness. The weight of the optical head (mobile part) is $3.5 \mathrm{~kg}$ and the weight of the electronic modules is around $4 \mathrm{~kg}$. The optical head has been designed to be easily set up on any mobile platform like a small aircraft or an automobile. It can be used for sampling, in a few minutes, aerosol plumes that are not horizontally uniform or for precisely retrieving aerosol vertical profile.

In this paper we first present the technical characteristics, the calibration procedure and a discussion on the recent evolutions of the instrument. Preliminary results of groundbased, airborne and automobile measurements are discussed and a comparison with lidar profiles is finally provided.

\section{Description of the instrument}

This instrument has two collimators both with approximately a $1.5^{\circ}$ full angle of field of view (FOV) and a four-quadrant detector with a $6^{\circ}$ angle of FOV. The first detector $(\mathrm{Si})$ covers visible and near-infrared ranges $(0.343 \mu \mathrm{m}, 0.380 \mu \mathrm{m}, 0.441 \mu \mathrm{m}, 0.499 \mu \mathrm{m}, 0.553 \mu \mathrm{m}$, $0.677 \mu \mathrm{m}, 0.869 \mu \mathrm{m}, 0.940 \mu \mathrm{m}, 1.023 \mu \mathrm{m})$ and the second detector (InGaAs) covers middle infrared $(1.14 \mu \mathrm{m}, 1.24 \mu \mathrm{m}$, $1.60 \mu \mathrm{m}, 1.646 \mu \mathrm{m}, 2.25 \mu \mathrm{m})$. PLASMA interference filters are similar to AERONET CIMEL sun photometer filters (Holben et al., 1998). The head can move in elevation (0$\left.90^{\circ}\right)$ and azimuth $\left(0-360^{\circ}\right)$, and rotation in azimuth can be continuous thanks to a ring power connector (Fig. 1). Hereinafter, we will limit our study to the channels that are in atmospheric windows (Fig. 2).

A microprocessor computes the position of the Sun based on time, latitude, and longitude, provided by a GPS system. It directs the sensor head to the Sun at which point the fourquadrant detector precisely tracks the Sun. If the tracking is disconnected when the aircraft is making a turn or due to the presence of clouds, then the GPS system takes over. The filters are located in two filter wheels which are rotated by a direct drive stepping motor. For a complete sequence, it takes $1.8 \mathrm{~s}$ for visible and near-infrared channels

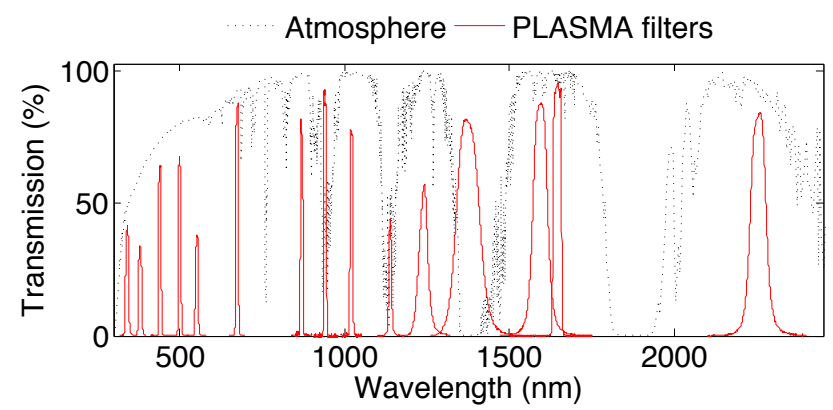

Fig. 2. PLASMA filter's transmission.

and $1.2 \mathrm{~s}$ for the middle-infrared channels. For common aircraft speeds $\sim 200 \mathrm{~km} \mathrm{~h}^{-1}$, a complete filter sequence corresponds to a distance of $100 \mathrm{~m}$ and $66 \mathrm{~m}$.

The voltage of both detectors is digitized by means of a delta-sigma ADC. The instrument is operated with a PC that records digital count for the visible and middle-infrared channels, latitude, longitude and altitude, speed and other flight parameters given by the GPS unit.

The $1.5^{\circ}$ full angle field of view of PLASMA is comparable to the $1.2^{\circ}$ of the CIMEL instrument. This relatively small FOV ensures that the instrument is less sensitive to atmospheric scattering into the FOV than instruments with broader FOV. The effect of atmospheric forward scattering on direct solar irradiance measurements increases with particle size, aerosol optical depth and instrument FOV; it has been shown that the impact is negligible (less than $1 \%$ of AOD) for FOV smaller than $2^{\circ}$ (Russell et al., 2004). A more recent study (Sinyuk et al., 2012) confirms that in most cases for a CIMEL-like instrument, this effect can be neglected excepted for heavy dust loadings where the relative error may reach $\sim 1 \%$ for an AOD of 3.5.

The InGaAs detector is temperature stabilized while the $\mathrm{Si}$ detector is not. The $1.023 \mu \mathrm{m}$ channel has been shown to be temperature sensitive. A correction derived from our laboratory measurements is applied to the detector signal using a coefficient of $0.35 \%{ }^{\circ} \mathrm{C}^{-1}$.

\section{Theoretical background}

AOD is derived from measurements of the atmospheric spectral transmission. Due to Bouguer-Lambert-Beer law the sun irradiance $E(\lambda, z)$ at a given wavelength $\lambda$ and at an altitude $z$ above sea level is expressed as (Bohren and Huffman, 1998):

$E(\lambda, z)=t_{\mathrm{g}}(\lambda, z) E_{0}(\lambda) e^{-\tau(\lambda, z) m}$,

where $E_{0}(\lambda)$ is the extraterrestrial sun irradiance; $t_{\mathrm{g}}(\lambda, z)$ the gaseous transmission; $m$ the air mass given by $1 / \cos \left(\theta_{\mathrm{s}}\right)$ when refraction and atmospheric curvature are neglected; $\theta_{\mathrm{s}}$ the solar zenith angle and $\tau(\lambda, z)$ the total optical depth of the 
atmosphere that is the sum of aerosol extinction and molecular (Rayleigh) optical depths:

$\tau(\lambda, z)=\tau_{\mathrm{ext}}^{a}(\lambda, z)+\tau_{\mathrm{ext}}^{m}(\lambda, z)$.

The digital signal $(\mathrm{DN}(\lambda, z))$ measured by the instrument is proportional to sun irradiance $E(\lambda, z)$ (the relative EarthSun distance is taken to be imbedded in the extraterrestrial DN value in order to simplify the nomenclature) one can write:

$\mathrm{DN}(\lambda, z)=t_{\mathrm{g}}(\lambda, z) \mathrm{DN}_{0}(\lambda) e^{-\tau(\lambda, z) / \cos \left(\theta_{\mathrm{s}}\right)}$.

From Eqs. (3) and (2) and after gaseous absorption correction, we can obtain aerosol extinction optical depth:

$$
\begin{aligned}
\tau_{\mathrm{ext}}^{a}(\lambda, z) & =\frac{1}{m}\left[\ln \left(\mathrm{DN}(\lambda) / t_{\mathrm{g}}(\lambda, z)\right)-\ln \left(\mathrm{DN}_{0}(\lambda)\right)\right] \\
& -\tau_{\mathrm{ext}}^{m}(\lambda, z) .
\end{aligned}
$$

To calculate gaseous absorption, i.e. absorption by oxygen, ozone, water vapor and other gases, we use spectral absorption lines provided in the $5 \mathrm{~S}$ code and the mid-latitude summer atmospheric model (Tanré et al., 1990).

Molecular scattering optical depth at the altitude $z$ is given by

$\tau_{\mathrm{ext}}^{m}(\lambda, z)=\tau_{\mathrm{ext}}^{m}\left(\lambda, z_{0}\right) \frac{P(z)}{P\left(z_{0}\right)}$,

where $\tau_{\mathrm{ext}}^{m}\left(\lambda, z_{0}\right)$ is the molecular optical depth at the surface level $z_{0}$ and $P\left(z_{0}\right)$ the associated pressure.

In the UV spectral range, the Rayleigh AOD is significant and has to be known with good accuracy to be properly corrected for. Since it depends on the atmospheric pressure, a pressure gauge has been included in the PLASMA instrument. Unfortunately, the measurements were not available at the time of our experiment and a crude estimate was performed using the equation: $P(z)=P\left(z_{0}\right) \exp (-z / 8.5)$, where $z$ is the altitude of the aircraft expressed in $\mathrm{km}$.

Since the aerosol extinction coefficient is the altitude derivative of AOD

$\sigma_{\mathrm{ext}}^{a}=\frac{\mathrm{d} \tau_{\mathrm{ext}}^{a}}{\mathrm{~d} z}$,

we can compare aerosol extinction coefficient derived by PLASMA and inferred from lidar backscatter profiles to validate lidar retrieval procedure.

In addition to the aerosol content, PLASMA can provide information on the aerosol size through the Ångström exponent. Based on spectral AODs, angstrom exponent is defined by Eq. (7) and is sensitive to the aerosol size (Schuster et al., 2006).

$\tau(\lambda)=\tau\left(\lambda_{0}\right)\left(\frac{\lambda}{\lambda_{0}}\right)^{-\alpha}$
More advanced retrieval (King et al., 1978) using spectral information have been developed and shown able to derive information on the aerosol size distribution $n(r, z)$ by inverting the following equation:

$\tau_{\mathrm{ext}}^{m}(\lambda, z)=\int_{z}^{\infty} \mathrm{d} z^{\prime} \int_{r_{\min }}^{r_{\max }} \pi r^{2} Q_{\mathrm{ext}}\left(m(\lambda), \frac{2 \pi r}{\lambda}\right) n\left(r, z^{\prime}\right) \mathrm{d} r$,

where $r$ is particle radius; $n(r, z)$ particle's size distribution; $m(\lambda)$ complex refractive index; $Q_{\text {ext }}$ extinction efficiency factor. Equation (8) assumes that the aerosol type does not depend on the altitude.

\section{Calibration and ground-based measurements}

For PLASMA calibration we used Langley method and intercalibration with master sun photometer CIMEL CE-318 that is used in Aerosol Robotic Network (AERONET) (Holben et al., 1998).

Langley plots are made to determine the spectral extraterrestrial voltage. The site has to be located at high altitude and in an area with a very stable aerosol regime. The Langley plot is a $\log$ of the DN against the optical air mass during the day (from Eq. 3) for the optical air mass range between 5 and 2. The intercept is the calibration coefficient, and the slope the optical thickness. The deviation of the intercept is a measure of the precision of the technique. If the aerosol loading is not constant, we may observe deviation from the linear regression line but such cases can be easily excluded at Mauna Loa and Izaña when Langley plots are performed. The Langley calibration is suitable for all spectral channels but the procedure is not straightforward since there are only a few sites that meet the requirements (Shaw, 1983).

Intercalibration between instruments is easier and of an accuracy comparable to Langley plots and can be done with near-simultaneous measurements of sun irradiance by PLASMA and CIMEL sun photometers at the same location. Spectral extraterrestrial voltage can be found from the relation:

$\frac{\operatorname{DN}_{0}^{\text {PLASMA }}(\lambda)}{\operatorname{DN}_{0}^{\mathrm{CIMEL}}(\lambda)}=\frac{\operatorname{DN}^{\mathrm{PLASMA}}(\lambda)}{\operatorname{DN}^{\mathrm{CIMEL}}(\lambda)}$.

The accuracy of AOD depends on the accuracy of calibration coefficients. A $1 \%$ error in calibration coefficient leads to inaccuracy $\Delta \mathrm{AOD} \approx 0.01$ at $m=1$, with the error decreasing by a factor of $1 / m$ as air mass increases. Usually the profile flights last around $30 \mathrm{~min}$ from 11:00 to 13:00 UTC; during this period the change of air mass is less than $5 \%$. Since a miscalibration results in a bias in AOD and the air mass is constant, it does not impact the value of the extinction coefficient that is the derivative of AOD (see Eqs. 4 and 6).

The first calibration campaign was organized at the Atmospheric Observatory in Izaña $\left(28.3^{\circ} \mathrm{N}, 16.5^{\circ} \mathrm{W}\right.$; alt. $\left.2391 \mathrm{~m}\right)$ 
in October 2009 for Langley approach and in Carpentras $\left(44.1^{\circ} \mathrm{N}, 5.1^{\circ} \mathrm{E}\right.$; alt. $\left.100 \mathrm{~m}\right)$ in March 2009 for intercalibration.

The calibration coefficients calculated with Izaña and Carpentras data in 2009 were applied to all data collected in Lille $\left(50.6^{\circ} \mathrm{N}, 3.1^{\circ} \mathrm{E}\right.$; alt. $\left.60 \mathrm{~m}\right)$ until March 2010 to obtain aerosol optical depth (AOD). The comparison with CIMEL measurements at common wavelengths $(0.34 \mu \mathrm{m}, 0.38 \mu \mathrm{m}$, $0.44 \mu \mathrm{m}, 0.67 \mu \mathrm{m}, 0.86 \mu \mathrm{m}, 1.02 \mu \mathrm{m}, 1.64 \mu \mathrm{m})$ showed a good agreement between the two instruments with with rms AOD differences being between 0.01 and 0.02 .

After modifications of some mechanical elements, a new calibration campaign was organized at Izaña in March 2010. Several measurements were then performed in LOA to sample different atmospheric conditions during 12 days in AprilJune 2010 and a better agreement with CIMEL master instrument was obtained with rms AOD differences $\sim 0.01$. The PLASMA calibration is not too far from the calibration of AERONET reference instruments $(0.002<\Delta$ AOD $<0.009)$ (Eck et al., 1999).

Once the technical development has been achieved, PLASMA was refurbished in March 2011. The stepping azimuth and zenith motors were replaced for better pointing capability and signal processing steps taken to improve the signal to noise ratio. We also replace all the filters, which required a new calibration of the instrument. After calibration the difference of AOD retrieved by PLASMA and CIMEL master instrument is less than 0.005 for all channels except $0.34 \mu \mathrm{m}$ channel (see Fig. 3).

The differences observed before 09:00 UTC and after 15:00 UTC may come from filter out-of-band leakage resulting from incomplete blocking of solar energy from outside the filter bandpass as seen in some AERONET CIMEL instruments. In the laboratory measurements of filters transmission, such leakage was not observed over $\pm 100 \mathrm{~nm}$ from the central wavelength. Differences may also come from a miscalibration of this channel. Knowing the calibration coefficient within $1 \%$ error only results in errors in the AOD of 0.025 for an air mass of 2.4 as anticipated around 07:30 in Lille in April. This effect would lead to a symmetrical behavior in the afternoon as observed in Fig. 3.

Since PLASMA has the same interference filters as CIMEL, we follow the AERONET calibration policy and the instrument is going to be calibrated every year.

Currently, we analyze only results in spectral bands that are present on both PLASMA and CIMEL instruments. Of course, PLASMA covers a larger spectral range with a $2.25 \mu \mathrm{m}$ channel that is very important for AOD inversion. Nevertheless at this stage we do not consider this wavelength since we cannot validate calibration coefficient with any other instrument.

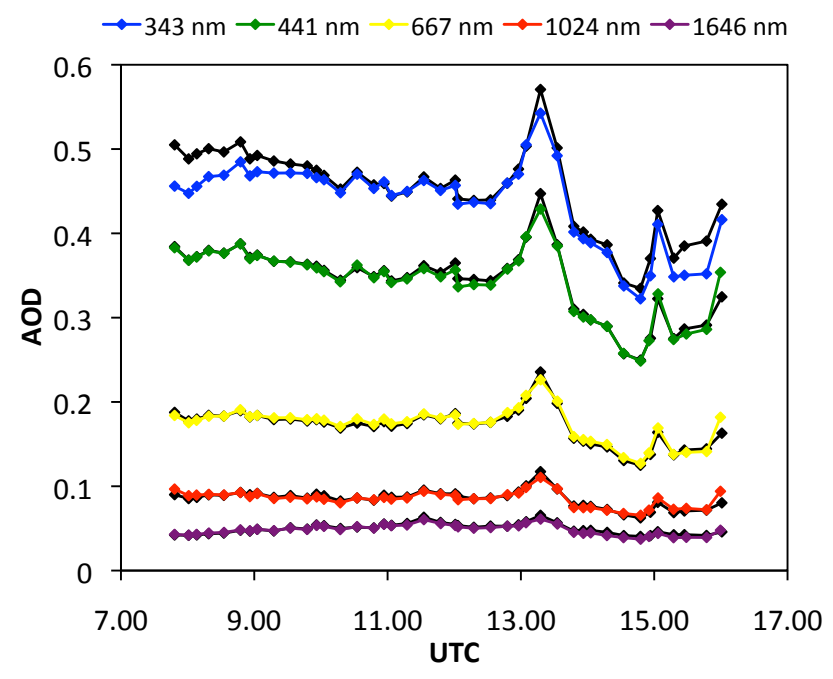

Fig. 3. Comparison of simultaneous ground-based measurements of PLASMA (colored lines) and CIMEL CE-318 (black lines) 18 April 2011.

\section{Airborne measurements}

In addition to ground-based measurements, several flights were performed in Lille: two technical flights in 2009, 6 flights in 2010 and 3 flights in 2011. We provide hereinafter results for flights performed after first improvements, i.e. since October 2010 only.

Figure 4 shows profiles of 4 flights in 2010-2011: 12 October 2010, 28 September 2011, 29 September 2011 and 15 October 2011 from the top to the bottom. The first column of graphs on the left presents the vertical profile of AOD at different wavelengths; the second is the profile of extinction coefficient; the third column on the right presents the comparison of extinction at $0.553 \mu \mathrm{m}$ with lidar retrievals at $0.532 \mu \mathrm{m}$. We use the Cloud and Aerosol Micro-LIDAR (CAML) CE 3702 manufactured by CIMEL. The instrument has been already described in Pelon et al. (2008) and Léon et al. (2009). The aerosol extinction profile as well as the effective extinction-to-backscatter ratio are retrieved using combination of lidar data and sun-photometer AOD (Léon et al., 2009).

To get extinction profile we decided to remove all noisy data due to the presence of clouds and then to average over 10 measurements. It means that we assume that the state of the atmosphere was stable over $30-60 \mathrm{~s}$, along $50-100 \mathrm{~m}$ in vertical direction and $2-4 \mathrm{~km}$ in horizontal direction. Altitudes below $500 \mathrm{~m}$ could not be observed by lidar. Lidar profiles presented on Fig. 4 are extended to the ground level by using the correction function based on independent measurements of AOD. Direct measurements of PLASMA can be used for validation of this function. The extinction profiles retrieved from lidar measurements are broadly consistent with PLASMA results, showing coarsely similar vertical 

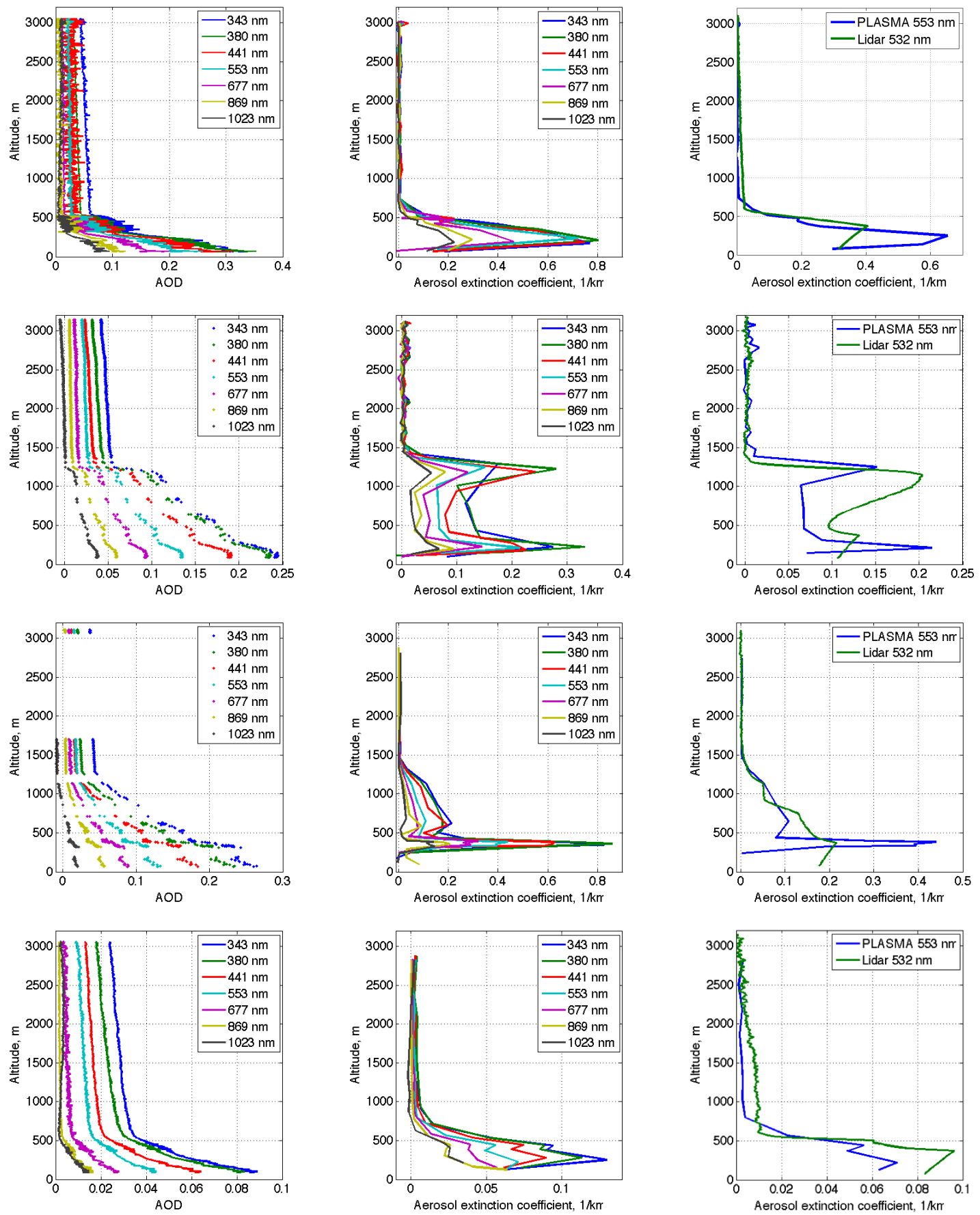

Fig. 4. PLASMA AOD (left), aerosol extinction coefficient (center) at 7 channels and aerosol extinction coefficient compared with lidar (right) as a function of the altitude acquired near Lille region the 12 October 2010, 28 September 2011, 29 September 2011 and 15 October 2011.

attributes. The best agreement between aerosol extinction coefficient profiles retrieved from PLASMA and lidar data was observed 15 October 2011 when the atmosphere was stable enough as seen from AOD profile.

For other days, differences might be explained by time and space variability of aerosol and clouds. On 29 September 2011 clouds were present in the vicinity and the turbidity was rather high and variable, between $0.15-0.20$ at $0.553 \mu \mathrm{m}$ around noon; as a result the data are noisier and a $50 \%$ difference of extinction coefficient at an altitude around $400 \mathrm{~m}$ is observed. Discrepancies can also result from spatial variability of the aerosol field; distance between both instruments was around $10 \mathrm{~km}$ when the airplane was on the ground, and more than $50 \mathrm{~km}$ when the plane was flying at the altitude 


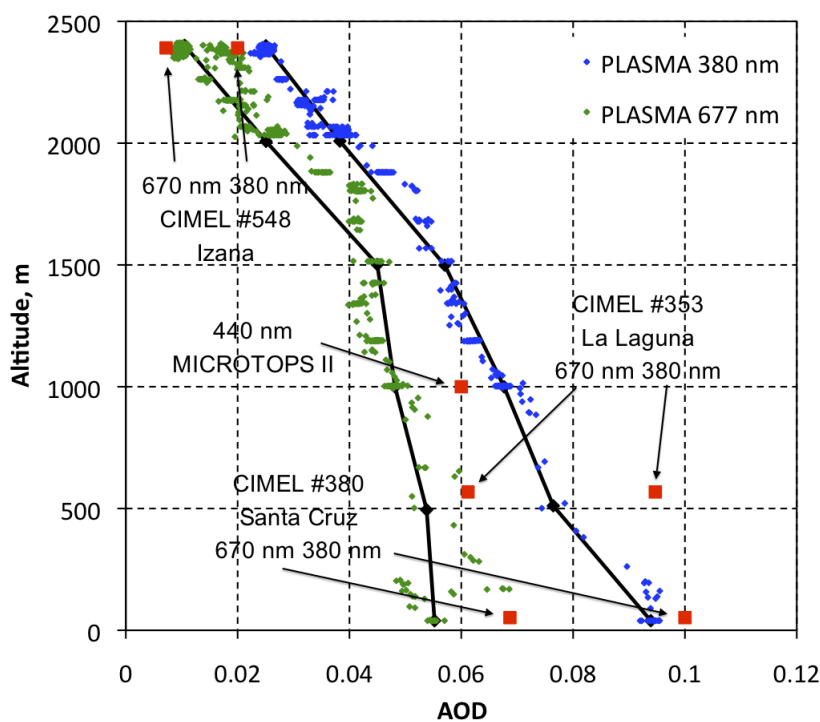

Fig. 5. Vertical profiles of AOD during automobile experiment 13 January 2011 on Tenerife island, Spain.

of $3000 \mathrm{~m}$. Moreover, the profiles take around $20 \mathrm{~min}$ and are compared to the nearest in the time lidar profile $(\Delta t \approx$ $15 \mathrm{~min}$ ). Despite these differences, the aerosol layers are located at the same altitude and we can say that both vertical profiles are coarsely consistent.

\section{Automobile measurements}

In addition to airborne measurements it is also possible to set up PLASMA on the roof of an automobile in order to obtain horizontal transects of AOD. In mountain areas, we can also get vertical profiles using measurements performed at different altitudes.

In January 2011 an experiment was successfully carried out on the island of Tenerife, Spain. The measurements were made from sea level to an altitude of $2400 \mathrm{~m}$ in one hour. Horizontal coverage area was about $30 \mathrm{~km}$ and we had the opportunity to compare the PLASMA AOD with the Izaña AERONET site (alt. $2391 \mathrm{~m}$ ) very close to the roadway. There are also two additional AERONET sites, La Laguna (alt. $590 \mathrm{~m}$ ) and Santa Cruz (alt. $54 \mathrm{~m}$ ), that were located at a distance of $40 \mathrm{~km}$ from our measurements.

The vertical profiles of AOD at $0.380 \mu \mathrm{m}$ and $0.677 \mu \mathrm{m}$ is compared to the three AERONET stations in Fig. 5. An additional measurement performed at the altitude of $1000 \mathrm{~m}$ using a sun photometer MICROTOPS II (Morys et al., 2001) is reported for $0.44 \mu \mathrm{m}$. Measurements of PLASMA are consistent with other instruments with $\triangle \mathrm{AOD} \sim 0.01$ and the differences for the low altitude sites could be explained by the distance between the instruments.

\section{Conclusions}

The new sun photometer that we have developed has been fully described. Following the calibration procedure recommended by AERONET, PLASMA provides AOD measurements with an accuracy of $0.005<\Delta$ AOD $<0.01$ over a wide spectral range.

Its capability to follow the sun when it moves is very attractive. Installed on an aircraft, vertical profiles of AOD and aerosol extinction coefficient can be so derived and compared to lidar retrievals. Overall, PLASMA is a user-friendly instrument, easy to install on moving platforms and performing well compared to other instruments.

Acknowledgements. This study has been funded by CNES (Centre National d'Études Spatiales), CNRS (Centre National de la Recherche Scientifique), the University of Lille, and Région Nord-Pas-de-Calais. Y. Karol is supported by a fellowship from CNES and CNRS. PLASMA calibration was performed at Izaña observatory using AERONET-EUROPE calibration center, supported by ACTRIS from European Union Seventh Framework Program (FP7/2007-2013) under grant agreement no. 262254. Emilio Cuevas-Agullo from the Meteorological State Agency of Spain (AEMET) is acknowledged for his help during the experiment in Tenerife. The authors are very thankful to AERONET for establishing and maintaining the sites used in this work.

Edited by: O. Dubovik

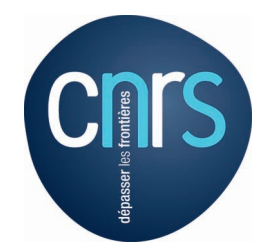

The publication of this article is financed by CNRS-INSU.

\section{References}

Asseng, H., Ruhtz, T., and Fischer, J.: Sun and Aureole Spectrometer for Airborne Measurements to Derive Aerosol Optical Properties, Appl. Optics, 43, 2146-2155, doi:10.1364/AO.43.002146, 2004.

Bohren, C. and Huffman, D.: Absorption and Scattering of Light by Small Particles, Wiley science paperback series, Wiley-VCH, 1998.

Eck, T. F., Holben, B. N., Reid, J. S., Dubovik, O., Smirnov, A., O'Neill, N. T., Slutsker, I., and Kinne, S.: Wavelength dependence of the optical depth of biomass burning, urban, and desert dust aerosols, J. Geophys. Res., 104, 31333-31349, doi:10.1029/1999JD900923, 1999.

Hansen, J., Sato, M., and Ruedy, R.: Radiative forcing and climate response, J. Geophys. Res., 102, 6831-6864, doi:10.1029/96JD03436, 1997.

Holben, B., Eck, T., Slutsker, I., Tanré, D., Buis, J., Setzer, A., Vermote, E., Reagan, J., Kaufman, Y., Nakajima, T., Lavenu, F., Jankowiak, I., and Smirnov, A.: AERONET - A Federated Instrument Network and Data Archive for Aerosol Character- 
ization, Remote Sens. Environ., 66, 1-16, doi:10.1016/S00344257(98)00031-5, 1998.

Kahn, R., Gaitley, B., Garay, M., Diner, D., Eck, T., Smirnov, A., and Holben, B.: Multiangle Imaging SpectroRadiometer global aerosol product assessment by comparison with the Aerosol Robotic Network, J. Geophys. Res., 115, D23209, doi:10.1029/2010JD014601, 2010.

Kaufman, Y. J., Tanré, D., and Boucher, O.: A satellite view of aerosols in the climate system, Nature, 419, 215-223, 2002.

King, M., Byrne, D., Herman, B., and Reagan, J.: Aerosol Size Distributions Obtained by Inversions of Spectral Optical Depth Measurements, J. Atmos. Sci., 35, 2153-2167, doi:10.1175/15200469(1978)035<2153:ASDOBI>2.0.CO;2, 1978.

Koren, I., Kaufman, Y. J., Remer, L. A., and Martins, J. V.: Measurement of the Effect of Amazon Smoke on Inhibition of Cloud Formation, Science, 303, 1342-1345, doi:10.1126/science.1089424, 2004.

Léon, J.-F., Derimian, Y., Chiapello, I., Tanré, D., Podvin, T., Chatenet, B., Diallo, A., and Deroo, C.: Aerosol vertical distribution and optical properties over M'Bour $\left(16.96^{\circ} \mathrm{W} ; 14.39^{\circ} \mathrm{N}\right)$, Senegal from 2006 to 2008, Atmos. Chem. Phys., 9, 9249-9261, doi:10.5194/acp-9-9249-2009, 2009.

Matsumoto, T., Russell, P., Mina, C., Ark, W. V., and Banta, V.: Airborne Tracking Sunphotometer, J. Atmos. Ocean. Tech., 4, 336-339, 1987.

Morys, M., Forrest, M., Hagerup, S., Anderson, S., Baker, A., Kia, J., and Walkup, T.: Design, calibration, and performance of MICROTOPS II handheld ozone monitor and Sun photometer, J. Geophys. Res., 106, 14573-14582, 2001.

Pelon, J., Mallet, M., Mariscal, A., Goloub, P., Tanré, D., Karam, D. B., Flamant, C., Haywood, J., Pospichal, B., and Victori, S.: Microlidar observations of biomass burning aerosol over Djougou (Benin) during African Monsoon Multidisciplinary Analysis Special Observation Period 0: Dust and Biomass-Burning Experiment, J. Geophys. Res., 113, D00C18, doi:10.1029/2008JD009976, 2008.

Ramanathan, V., Crutzen, P., Kiehl, J., and Rosenfeld, D.: Aerosols, Climate, and the Hydrological Cycle, Science, 294, 2119-2124, doi:10.1126/science.1064034, 2001.

Remer, L., Kaufman, Y., Tanré, D., Mattoo, S., Chu, D., Martins, J., Li, R., Ichoku, C., Levy, R., Kleidman, R., Eck, T., Vermote, E., and Holben, B.: The MODIS Aerosol Algorithm, Products, and Validation, J. Atmos. Sci., 62, 947-973, doi:10.1175/JAS3385.1, 2005.
Russell, P. B., Livingston, J. M., Dubovik, O., Ramirez, S. A., Wang, J., Redemann, J., Schmid, B., Box, M., and Holben, B. N.: Sunlight transmission through desert dust and marine aerosols: Diffuse light corrections to Sun photometry and pyrheliometry, J. Geophys. Res., 109, D08207, doi:10.1029/2003JD004292, 2004.

Schmid, B., Redemann, J., Russell, P., Hobbs, P., Hlavka, D., Mcgill, M., Holben, B., Welton, E., Campbell, J., Torres, O., Kahn, R., Diner, D., Helmlinger, M., Chu, D., Robles-Gonzalez, C., and de Leeuw, G.: Coordinated airborne, spaceborne, and ground-based measurements of massive thick aerosol layers during the dry season in southern Africa, J. Geophys. Res.-Atmos., 108, 8496, doi:10.1029/2002JD002297, 2003.

Schuster, G. L., Dubovik, O., and Holben, B. N.: Angstrom exponent and bimodal aerosol size distributions, J. Geophys. Res., 111, D07207, doi:10.1029/2005JD006328, 2006.

Shaw, G.: Sun Photometry, Bulletin of the American Meteorological Society, 64, 4-10, doi:10.1175/15200477(1983)064<0004:SP>2.0.CO;2, 1983.

Sinyuk, A., Holben, B., Smirnov, A., Eck, T., Slutsker, I., Schafer, J., Giles, D., and Sorokin, M.: Assessment of error in aerosol optical depth measured by AERONET due to aerosol forward scattering, Geophys. Res. Lett., 39, L23806, doi:10.1029/2012GL053894, 2012.

Tanré, D., Deroo, C., Duhaut, P., Herman, M., Morcrette, J., Perbos, J., and Deschamps, P.: Description of a computer code to simulate the satellite signal in the solar spectrum: the $5 \mathrm{~S}$ Code, Int. J. Remote Sens., 11, 659-668, 1990.

Tanré, D., Bréon, F. M., Deuzé, J. L., Dubovik, O., Ducos, F., François, P., Goloub, P., Herman, M., Lifermann, A., and Waquet, F.: Remote sensing of aerosols by using polarized, directional and spectral measurements within the A-Train: the PARASOL mission, Atmos. Meas. Tech., 4, 1383-1395, doi:10.5194/amt-4-1383-2011, 2011.

Winker, D., Pelon, J., Coakley, J., Ackerman, S., Charlson, R., Colarco, P., Flamant, P., Fu, Q., Hoff, R., Kittaka, C., Kubar, T., Le Treut, H., McCormick, M., Mégie, G., Poole, L., Powell, K., Trepte, C., Vaughan, M., and Wielicki, B.: The CALIPSO Mission: A Global 3D View of Aerosols and Clouds, B. Am. Meteorol. Soc., 91, 1211-1229, doi:10.1175/2010BAMS3009.1, 2010. 